\title{
Resistance of SOD2-transgenic petunia line to oxidative stress
}

\author{
Su Young Lee $\cdot$ Bong Hee Han $\cdot$ Yeong-Tae Kim $\cdot$ Jin-Seog Kim
}

Received: 16 November 2010 / Accepted: 31 November 2010

(c) Korean Society for Plant Biotechnology

\begin{abstract}
SOD2-transgenic $\mathrm{T}_{3}$ petunia line (A2-36-2-1-1-35) was treated with different levels of methyl viologen (MV) to determine its resistance to oxidative stress. Four (4) levels of MV $(0,100,200$, and $400 \mu \mathrm{M})$ were applied. The SOD2transgenic $T_{3}$ petunia line exhibited a very significant oxidative stress resistance at the highest MV concentration $(400 \mu \mathrm{M})$ treatment compared to non-transgenic plant. RNA and protein expression of SOD2 transgene and higher parenchyma cell density in the transgenic petunias exhibiting resistance to oxidative stress proves its contribution to the expression of its resistance to oxidative stress.
\end{abstract}

Keywords transgenic petunia, oxidative stress, resistance, methyl viologen (MV)

\section{Introduction}

It is necessary to develop new cultivar resistant to environmental stresses such as rainfall, humidity, and air pollution for petunia (Petunia hybrida L.), since it is one of the promising hedge garden flowers planted along the roads in Korea together with some pansy plants during spring to late summer. However, the difficulty to develop new cultivar resistant to abiotic stress through conventional breeding

S. Y. Lee $(\square)$

Floricultural Research Division, National Institute of

Horticultural \& Herbal Science, Rural Development

Administration, Suwon 441-310, Korea

e-mail: 1sy8542224@korea.kr

B. H. Han

The Foundation of Ag. Tech. Commercialization and Transfer, Suwon 441-857, Korea

Y.-T. Kim

Genomics Division, National Academy of Agricultural Science, Rural Development Administration, Suwon 441-857, Korea

J.-S. Kim

Chemical Biotechnology Research Center, Korea Research Institute of Chemical Technology (KRICT) Daejeon 305-800, Korea technique has led to the use of genetic transfer method to further improve plant resistance to abiotic stresses (Fang et al. 2002; Moon et al. 2003; Tang et al. 2004a, 2004b, 2007; Kim et al. 2005). Notably, McKersie et al. (1996) and Wang et al. (2005) reported that the transgenic MnSOD alfalfa and rice exhibited reduction of injury from water deficit and drought, respectively. In previous study, it was reported that SOD2 transgene inherited and expressed stably in $T_{1}$ and $T_{2}$ lines of SOD2 (MnSOD)-transgenic petunia plants (Lee et al. 2009a, 2009b). Meanwhile, success of the gene transfer to enhance resistance to abiotic stress needs to identify resistance of transgenic plants to oxidative stress. Many researchers had identified transgenic plants resistance to oxidative stress using methyl viologen (MV, paraquat) (Kim et al. 2005; Kwon et al. 2002; Lee et al. 2007; Lim et al. 2007; Moon et al. 2003; Tang et al. 2004, 2008), which induces treatment of superoxide anion $\left(\mathrm{O}_{2}^{-}\right)$, singlet oxygen, as well as hydroxyl and peroxy radicals (Kim et al. 1986; Suntres 2002). Thus, this study was conducted to determine the resistance of SOD2-transgenic $T_{3}$ petunia line to oxidative stress using different MV treatment concentrations.

\section{Materials and methods}

Plant materials

SOD2 transgenic ( $T_{3}$ and $T_{4}$ lines) plants obtained from Wongyo A2-36 (purebred line of petunia) were used as plant materials. Only one (1) copy transfer of the transgene into SOD2-transgenic primary plants $\left(\mathrm{T}_{0}\right)$ was identified through Southern analysis in our previous study (Lee et al. 2009a). Likewise, integration of the SOD2 gene in the petunia genome at a single locus was identified through segregation ratio (1:0) of the transgene in $T_{1}$ and $T_{2}$ plants (Lee et al. 2009b). 
Treatment of MV on whole plant

The transgenic $T_{3}$ line seedlings grown for twenty days after being sown on plastic box with cultural medium (400 g) mixed with perlite (SungHyun Perlite Co., South Korea) and commercial compost, were transplanted to plastic pot $(15 \mathrm{~cm})$ with previous culture medium. After cultivation for 15 days in the greenhouse, about $3.75 \mathrm{~mL}$ of $\mathrm{MV}$ concentrations $(0,100,200,400 \mu \mathrm{M})$ dissolved in $20 \%$ acetone solution supplemented with $0.1 \%(\mathrm{w} / \mathrm{v})$ Tween 20 was sprayed on the transgenic $\mathrm{T}_{3}$ line (4 plants per treatment) using a sprayer. No damage was observed in the plants with the applications of $20 \%$ acetone solution. Each treatment was repeated three times. Injury of the transgenic plants was visually observed with a $0 \sim 100 \%$ rating table (0: no damage, 100 : completely killed) by three researchers.

\section{Western analysis}

Two days after treatment of MV, total soluble proteins were extracted from leaves of the transgenic $T_{3}$ line plants treated with MV concentrations at $0,100,200$, and $400 \mu \mathrm{M}$ using distilled water. Twenty (20) $\mu \mathrm{g}$ of protein quantified through Bradford assay was mixed with 5X SDS-PAGE gel loading buffer and separated on $12.5 \%$ SDS polyacrylamide gel. The electrophoresed proteins were blotted onto a PVDF membrane with transfer buffer (Tris $25 \mathrm{mM}$, glycine $192 \mathrm{mM}$, SDS $0.1 \%, \mathrm{pH} 8.3$ ) by using a semidry electroblotter (Bio-Rad, U.S.A.). The membrane blot was incubated first in anti-SOD2 polyclonal antibody solution at a 1:500 dilution. After primary antibody incubation, the membrane was incubated again in alkaline phosphotase-conjugated goat anti-rabbit $\operatorname{IgG}(\mathrm{H}+\mathrm{L})$ (KPL, U.S.A.) solution at a 1:2500 dilution, and then visualized by color metric detection (Promega, U.S.A.).

Northern analysis

Total RNA was isolated from leaves $(100 \mathrm{mg})$ of the transgenic lines $\left(\mathrm{T}_{3}\right.$ and $\left.\mathrm{T}_{4}\right)$ with the RNeasy Plant Mini Kit (QIAGEN, Germany) following the manufacturer's recommendations. $\mathrm{T}_{4}$ line came from self-pollination of $\mathrm{T}_{3}$ line which showed outstanding resistance to oxidative stress due to treatment of MV $400 \mu \mathrm{M}$ based on the preceding experiment (MV treatment on whole plant). Quality and concentration evaluation of the isolated RNA were done by gel electrophoresis (1\%, RNase-free) and spectrophotometer $(260 / 280 \mathrm{~nm})$.

\section{Microscopic observation}

A microscopic observation of leaf tissues of the SOD2transgenic $T_{3}$ line plants showing symptom like necrosis was conducted seven days after spraying with MV 400 $\mu \mathrm{M}$. Following Luft (1973), samples were prepared and stained with periodic acid staining (PAS) before viewing them with Axioskop 2 light microscope (Carl Zeiss Co., Germany).

\section{Results and Discussion}

Determination of oxidative stress resistance of SOD2-transgenic $\mathrm{T}_{3}$ line

SOD2 transgenic $\mathrm{T}_{3}$ line plants were treated with four (4) MV concentrations. In previous study, it was found that Wongyo A2-36 was more sensitive than any other control line (Lee and Han 2008). This means that the oxidative stress resistance of the SOD2 transgenic line from Wongyo A2-36 could positively be enhanced by over-expression of the transgene. As shown in Figure 1A to 1B, the leaf injury of the transgenic line caused by MV treatments was observed a day after the treatment and became severe thereafter. As previously reported by Kim et al. (2005) and Asada et al. (1977), generally an oxidative stress response in most plants varies according to their growth stage, younger leaf tissues were less damaged than the older ones. Minimal injury was observed in all treatments for the transgenic line compared to the control. The resistance to MV was identified at the second and fifth days as shown in Figure $1 \mathrm{C}$ to $1 \mathrm{~F}$. The transgenic line exhibited the least damage throughout the observation period. Based on these results, SOD2 gene appears to function under more extreme oxidative stress. Expectedly, the transgenic line exhibited lesser percent (\%) damage/injury in all treatments compared to the control even during the $7^{\text {th }}$ day after treatment as shown in Table 1. Notably, the transgenic line revealed highly significant resistance to oxidative stress as shown by its minimal injury even at MV $400 \mu \mathrm{M}$ treatment.

Microscopic observation of leaf necrosis in SOD2-transgenic $\mathrm{T}_{3}$ line

Figure 2D shows leaf necrosis observed on the new shoots of transgenic $\mathrm{T}_{3}$ line plants treated with MV 100 to $200 \mu \mathrm{M}$ around 7 days after treatment. Microscopic observation revealed some variations between the leaf tissues of trans- 


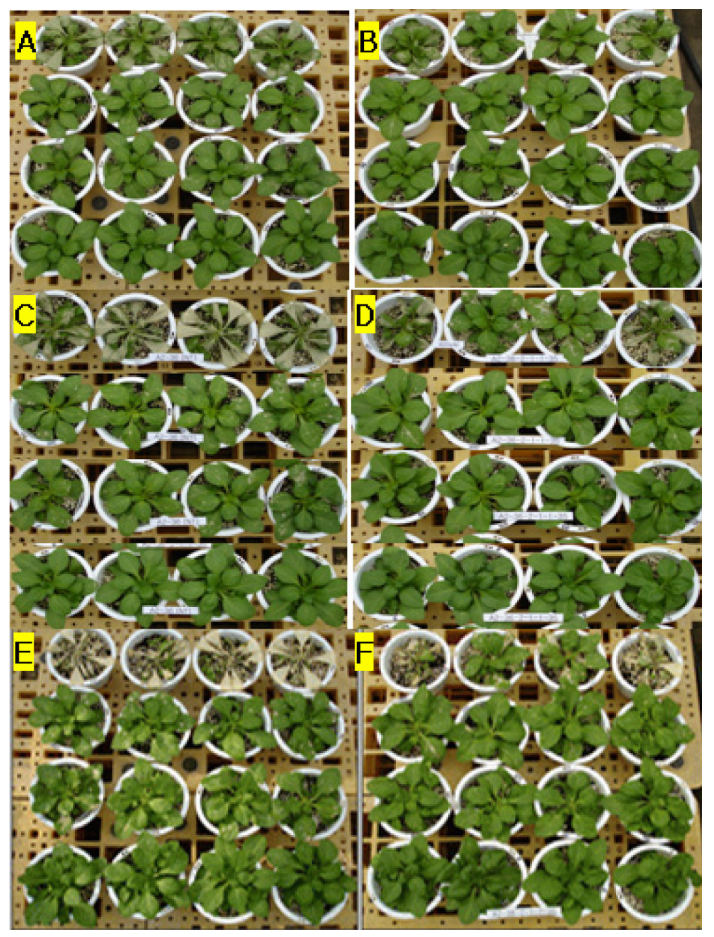

Fig. 1 Responses of SOD2-trangenic $T_{3}$ petunia line A2-362-1-1-35 one day (A and $\mathrm{B})$, two days (C and D) and five days (E and F) after spraying different methyl viologen (MV) (paraquat) concentrations in the greenhouse. MV levels $(0,100,200$, and $400 \mu \mathrm{M})$ were sprayed starting from the bottom $(0 \mu \mathrm{M})$ to the fourth row $(400 \mu \mathrm{M})$ of the petunia lines, respectively. (A), (C), and (E) Wongyo A2-36 (non-transgenic plant); (B), (D) and (F) A2-36-2-1-1-35 genic and non-transgenic plants. Only a small number of or no cell (with chlorophyll) and normal conductive tissues were observed in the transgenic leaves treated with MV. Likewise, only few differences were observed between palisade parenchyma and spongy parenchyma, and there was little or no space between parenchyma cells, as shown in Figure 2E. The higher cell density due to this narrow space in the parenchyma cells contributed further enhancement of resistance to oxidative stress of the transgenic $T_{3}$ line plants as reported by Barth and Conklin (2003) and Konarska (2010). Meanwhile, the leaf necrosis symptom disappeared within fifteen days after treatment as shown in Figure 2F. The symptom disappearance at a reasonable period after treatment of MV suggested that the symptom is a marker of plant resistance under oxidative stress.

Protein synthesis and RNA expression of the transgene of SOD2-transgenic $T_{3}$ and $T_{4}$ lines

It was identified by Northern and Western blot analysis that SOD2 gene products expressed in the transgenic lines exhibiting highly significant resistance to oxidative stress compared to control. It was confirmed that the protein, which was not synthesized in the control, was fully synthesized in the leaves on the second day after being applied with the treatment of MV $400 \mu \mathrm{M}$ (Fig. 3). Likewise, it was

Table 1 Injury (\%) of SOD2-trangenic petunia $T_{3}$ line 7 days after spraying different methyl viologen (MV) (paraquat) concentrations in the greenhouse

\begin{tabular}{cccccc}
\hline Genotype & No. of transgenic plants & \multicolumn{4}{c}{ Visual injury (\%) } \\
\cline { 3 - 6 } & & MV $0 \mu \mathrm{M}$ & MV 100 $\mu \mathrm{M}$ & MV 200 $\mu \mathrm{M}$ & MV 400 $\mu \mathrm{M}$ \\
\hline A2-36-2-1-1-35 & 12 & $0 \pm 0^{z}$ & $2.5 \pm 2.0$ & $4.5 \pm 4.5$ & $74.1 \pm 18.1$ \\
Wongyo A2-36 (NT) & 12 & $0 \pm 0$ & $12.5 \pm 10.9$ & $8.7 \pm 4.3$ & $98.3 \pm 3.8$ \\
\hline
\end{tabular}

${ }^{\mathrm{Z}}$ Mean \pm Standard deviation
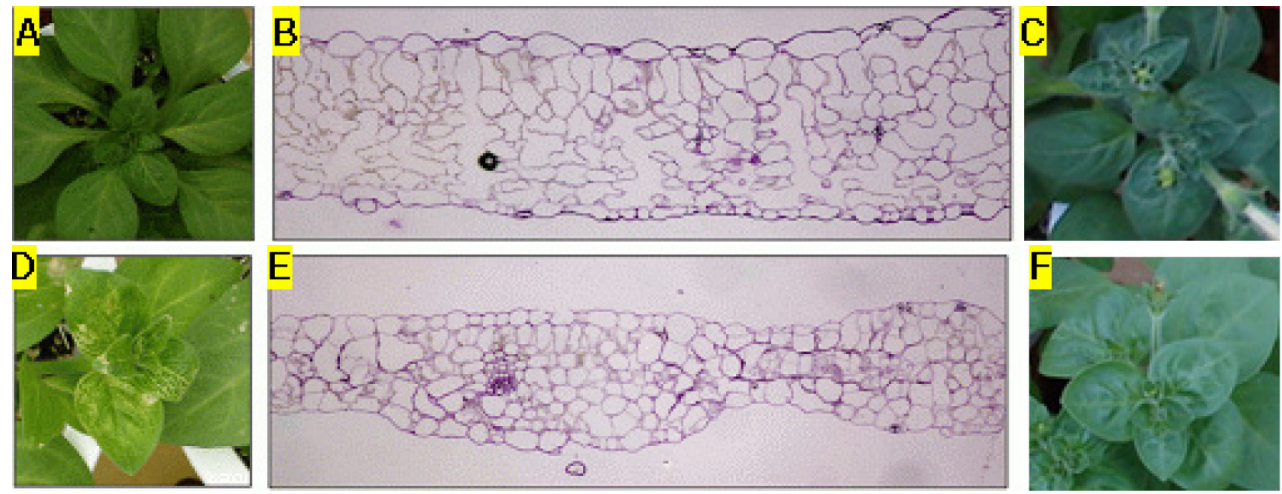

Fig. 2 Microscopic observation of non-transgenic petunia plant and SOD2-transgenic petunia $\mathrm{T}_{3}$ plant leaf tissues showing necrosis 7 days after spraying with methyl viologen (MV) (paraquat) 100 to $200 \mu \mathrm{M}$. (A), (B) and (C): non-transgenic plants Wongyo A2-36; (D), (E), and (F): SOD2-transgenic petunia $\mathrm{T}_{3}$ line A2-36-2-1-1-35 plants. (A) and (D) are non-transgenic line and A2-36-2-1-1-35 plants 7 days after treatment without and with MV, respectively. (B) and (E) are microscopic photos of (A) and (D), respectively. (C) and (F) showing plants 18 days after treatment without and with MV $400 \mu \mathrm{M}$, respectively 


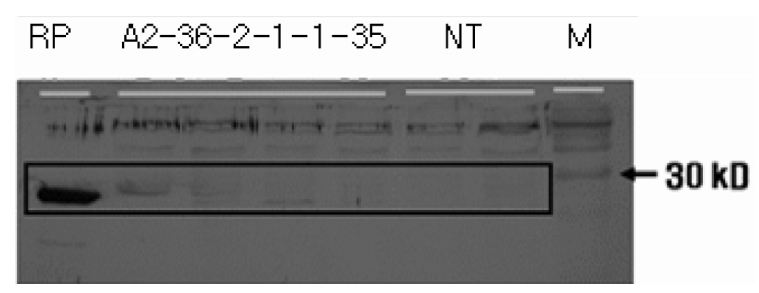

Fig. 3 Protein synthesis of transgene in SOD2-transgenic petunia $\mathrm{T}_{3}$ line A2-36-2-1-1-35 plants 2 days after spraying methyl viologen (MV) (paraquat) $400 \mu \mathrm{M}$ identified through Western blot analysis. RP: recombinant protein of transgene; NT: nontransgenic plants; M: protein molecular weight standards

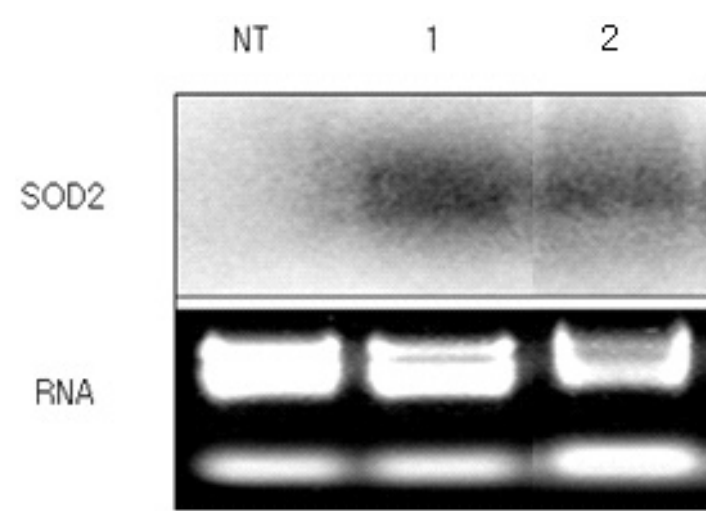

Fig. 4 Transgene expression in SOD2-transgenic petunia plants identified through Northern blot analysis. NT, non-transgenic plants; 1, A2-36-2-1-1-35 ( $\left.\mathrm{T}_{3}\right)$; 2, A2-36-2-1-1-35 $\left(\mathrm{T}_{4}\right)$

revealed that the RNA of target gene in the transgenic $T_{3}$ line (not treated with $\mathrm{MV}$ ) and the $\mathrm{T}_{4}$ line (obtained from self-pollination of $\mathrm{T}_{3}$ plant showing high resistance to $\mathrm{MV}$ $400 \mu \mathrm{M}$ ) was expressed (Fig. 4). These results confirmed that the resistance to oxidative stress in the transgenic generations was due to the activation of the SOD2 transgene.

\section{Conclusion}

This study revealed that SOD2-transgenic $\mathrm{T}_{3}$ petunia line (A2-36-2-1-1-35) was resistant to oxidative stress induced with treatment of high MV concentration $(400 \mu \mathrm{M})$ compared to non-transgenic plant. The expressed RNA and synthesized protein were determined. Furthermore, the RNA of the transgene was expressed even in the $T_{4}$ plants obtained from self-pollination of $\mathrm{T}_{3}$ plants which showed high resistance even under treatment of MV $400 \mu \mathrm{M}$. Therefore, the SOD2-transgenic petunia line exhibiting resistance to oxidative stress is considered promising genetic material for breeding new petunia cultivar resistant to abiotic stress.

\section{Acknowledgement}

The authors are grateful to Ms. Kyoung Ran Do and Mr. Jeong Ho Kim for the technical assistance during the conduct of the microscopic observation and Northern blot analysis. This work was supported by a grant from the National Institute of Horticultural \& Herbal Science and conducted as part of BioGreen 21 program, Rural Development Administration, Republic of Korea.

\section{References}

Asada K, Takahashi MA, Tanaka K, Nakano Y (1977) Formation of active oxygen and its fate in chloroplasts. In: Hayashi $\mathrm{O}$ and Asada K (eds), Biochemical and medical aspects of active oxygen. Univ Park Press Baltimore: 45-62

Barth C, Conklin PL (2003) The lower cell density of leaf parenchyma in the Arabidopsis thaliana mutant lcd1-1 is associated with increased sensitivity to ozone and virulent Pseudomonas syringae. The Plant J 35:206-218

Fang GC, Hanau RM, Vaillancourt LJ (2002) The SOD2 gene, encoding a manganese-type superoxide dismutase, is upregulated during conidiogenesis in the plant pathogenic fungus Colletotrichum graminicola. Fungal Genetics and Biology 36:155-165

Kim KU, Kim DU, Kwon ST (1986) Development of herbicide (paraquat) tolerant plant through tissue culture Korea J Weed Sci 61:191-200

Kim KY, Kwon SY, Lee HS, Hur Y, Bang JW, Kwak SS (2003) A novel oxidative stress-inducible peroxidase promoter from sweetpotato: molecular cloning and characterization in transgenic tobacco plants and cultured cells. Plant Mol Biol 51: 831-838

Kim JS, Lee BH, Kwon SY, Kim YH, Kim SH, Cho KY (2005) Antioxidative responses of transgenic tobacco plants expressing both superoxide dismutase and ascorbate peroxidase in chloroplasts to several herbicides. Kor J Plant Biotech 32: 97-103

Konarska A (2010) Effects of aluminum on growth and structure of red pepper (Capsicum annuum L.) leaves. Acta Physiol Plant 32:145-151

Kwon DY, Jeong YI, Lee HS, Kim JS, Cho KY, Allen RD, Kwak SS (2002) Enhanced tolerance of transgenic tobacco plants expressing both superoxide dismutase and ascorbate peroxidase in chloroplasts against methyl viologen- mediated oxidative stress. Plant Cell and Environment 25:873-882

Lee SY, Han BH (2008) Development of petunia resistant to environmental stress. In: National Horticultural Research Institute (eds) Report of horticultural experimental studies in 2007 333-342 (in Korean)

Lee SY, Han BH, Cho AY (2009a) Inheritance and expression of transgene in SOD2-transgenic petunia descendants and their morphological traits. Kor J Plant Biotech 36:289-293 
Lee SY, Han BH, Noh EW, Kwak SS (2009b) Transfer of SOD2 or NDP kinase 2 genes into purebred lines of petunia. Kor J Plant Biotech 36:144-148

Lee SH, Ahsan N, Lee KW, Lim DH, Lee DG, Kwak SS, Kwon SY, Kim TH, Lee BH (2007) Simultaneous overexpression of both $\mathrm{CuZn}$ superoxide dismutase and ascorbate peroxidase in transgenic tall fescue plants confers increased tolerance to a wide range of abiotic stresses. J Plant Physiology 164: 1626-1638

Lim S, Kim YH, Kim SH, Kwon SY, Lee HS, Kim JS, Cho KY, Paek KY, Kwak SS (2007) Enhanced tolerance of transgenic sweetpotato plants that express both CuZnSOD and APX in chloroplasts to methyl viologen-mediated oxidative stress and chilling. Mol Breeeding 19:227-239

Luft JH (1973) Compounding of Luft's epon embedding medium for use in electron microscopy with reference to anhydride. Epoxide ratio adjustment Mikroskopie 29:337-342

McKersie BD, Bowley SR, Harjanto E, Leprince O (1996) Water deficit tolerance and field performance of transgenic alfalfa overexpressing superoxide dismutase. Plant Physiol 111: $1177-1188$

Moon H, Lee B, Choi G, Shin D, Prasad DT, Lee O, Kwak SS, Kim DH, Nam J, Hahk J, Hong C, Lee SY, Cho MJ, Lim CO (2003) NDP kinase 2 interacts with two oxidative stressactivated MARKs to regulate cellular redox state and enhances multiple stress tolerance in transgenic plants. PNAS 100: 358-363

Suntres Z (2002) Role of antioxidants in paraquat toxicity. Toxicology 180:65-77

Tang L, Kwon SY, Kim MD, Kim JS, Kwak SS, Lee HS (2007) Enhanced tolerance to oxidative stress of transgenic potato (cv. Superior) plants expressing SOD and APX in chloroplasts. Kor J Plant Biotech 34:299-305

Tang L, Kwon SY, Yun DJ, Kwak SS, Lee HS (2004a) Selection of transgenic potato plants expressing NDP Kinase 2 gene with enhanced tolerance to oxidative stress. Kor J Plant Biotech 31:191-195

Tang L, Kwon SY, Kwak SS, Sung CK, Lee HS (2004b) Selection of transgenic potato plants expressing both CUZNSOD and APX in chloroplasts with enhanced tolerance to oxidative stress. Kor J Plant Biotech 31:109-113

Tang L, Kim MD, Yang KS, Kwon SY, Kim SH, Kim JS, Yun DJ, Kwak SS, Lee HS (2008) Enhanced tolerance of transgenic potato plants overexpressing nucleoside diphosphate kinase 2 against multiple environmental stresses. Transgenic Res 17: 705-715

Wang FZ, Wang QB, Kwon SY, Kwak SS, Su WA (2005) Enhanced drought tolerance of transgenic rice plants expressing a pea manganese superoxide dismutase. J Plant Physiol 162: 465-472 